\title{
Erläuterungen zur Zitierweise
}

Texte Hölderlins werden nach der ,Frankfurter Hölderlin Ausgabe ${ }^{6}$ zitiert, und zwar mit Nachweisen im laufenden Text nach diesem Muster: ,FHA 6, 25, Z./V. $10^{6}$ (Band, Seite, Zeile bzw. Vers). Ferner steht FHA Einl. für den Einleitungsband (1975), FHA Suppl. III für die Faksimile-Edition des Homburger Folioheftes (1986), FHA Suppl. III Beil. für die Beilage zum Faksimile, die eine editorische, entstehungs- und überlieferungsgeschichtliche Einleitung sowie eine vollständige Transkription des Heftes enthält. In vielen Fällen wird auch direkt nach dieser Handschrift zitiert, z. B. ,HF 30, Z. 26. Dabei bezeichnet die erste Zahl die Handschriftenseite (1-92), die zweite die Zeile (nach der Zählung, die sich in der Beilage am Rande der Transkriptionen findet); die Lesungen entsprechen nicht in allen Fällen denen der FHA.

Texte, die in der FHA noch nicht publiziert sind, werden nach der ,Großen Stuttgarter Ausgabe 6 nach folgendem Muster angeführt: ,StA II.1, 4, Z./V. 2' (Band, Teilband, Seite, Zeile bzw. Vers). Zusätzlich wird für den sechsten und siebten Band die Nummer der Briefe angegeben; für die Bände sieben und acht übernehme ich Becks Kürzel $L D$ für ,Lebensdokument' und $R W$ für ,Rezensionen und Würdigungen'. Weitere Hölderlin-Ausgaben werden mit den unten jeweils hinter den (chronologisch geordneten) bibliographischen Angaben genannten Kürzeln angeführt.

Zitate aus Texten anderer Autorinnen und Autoren werden in den Fußnoten in der Regel durch Angabe des Nachnamens, des Erscheinungsjahrs der benutzten Ausgabe bzw. (bei Gesamtausgaben und besonders häufig herangezogenen Texten) eines Kürzels sowie (gegebenenfalls) des Bandes, der Seitenzahl und (bei Gedichten oder Epen) des Verses nachgewiesen. Dabei stehen Jahreszahl oder Kürzel und Seitenzahl nur dann in Klammern, wenn im betreffenden syntaktischen Zusammenhang unmittelbar vom $\mathrm{Au}-$ tor bzw. der Autorin die Rede ist, also: ,Dazu schreibt Binder $(1982,10)$...; ; aber ,Cf. dazu Beißner 1961, 32.' Die Wörterbücher von Zedler, Adelung und Grimm werden ohne Kürzel zitiert; die Jahreszahl folgt in diesen Fällen in Klammern hinter der Bandangabe. Weitere Abweichungen von dem hier eingeführten Schema werden bei den betreffenden Literaturangaben erläutert. Das Literaturverzeichnis dient vor allem der möglichst problemlosen Auffindung der Quellenangaben und ist daher nicht systematisch, sondern durchgehend alphabetisch geordnet; Namen und Jahreszahlen/Kürzel sind fett gesetzt. Wird eine andere als die Erstausgabe herangezogen, vermerke ich das Ersterscheinungsjahr hinter dem Titel; bei Übersetzungen gebe ich zudem die Originalsprache an.

Neben den allgemein eingeführten Abkürzungen verwende ich HJb für ,HölderlinJahrbuch ${ }^{6}$ und $L p H$ für ,Le pauvre Holterling. Blätter zur Frankfurter Ausgabe'. 